\title{
Why do students quit medical school far less often in Canada than in other countries?
}

— Cite as: CMAJ 2019 February 11;191:E174-5. doi: 10.1503/cmaj.109-5704

Posted on cmajnews.com on Jan. 23, 2019.

$\mathrm{J}$ efferson Gatrall was about halfway through medical school at Dalhousie University when he realized he didn't fit in. "I was used to the humanities and a certain style of critical thinking," he recalled. During undergrad, he engaged other students in long discussions about what they were learning. In medical school, most of the students around him studied independently. "There was a certain culture mismatch."

But Gatrall didn't tell anyone he was thinking of quitting, not even his close friends. "I was very secretive about it," he said. He applied to a PhD program and didn't return to medical school. But he doesn't regret his year studying medicine. Today, he's the director of an undergraduate medical humanities program, which blends science and medicine with literature, history and philosophy.

"People ask what jobs they can get afterward," he said. He tells them that career paths aren't always linear and that they'll find their way.

Gatrall's story, however, is an exception. There are very few medical school dropouts in Canada. In 2017, only 53 students left medical school, representing $0.5 \%$ of the student body, according to data from the Association of Faculties of Medicine of Canada. Of those, 21 dropped out in the first year, like Gatrall.

In the United States, by comparison, the medical school attrition rate has been about 3.3\% for decades. That increases to $4.8 \%$ for combined bachelor-MD programs. In the United Kingdom, where undergraduate degrees aren't required to study medicine, the dropout rate is even higher. About 300 of the UK's 6000 medical students (5\%) quit every year, and another 1600 are asked to leave for poor

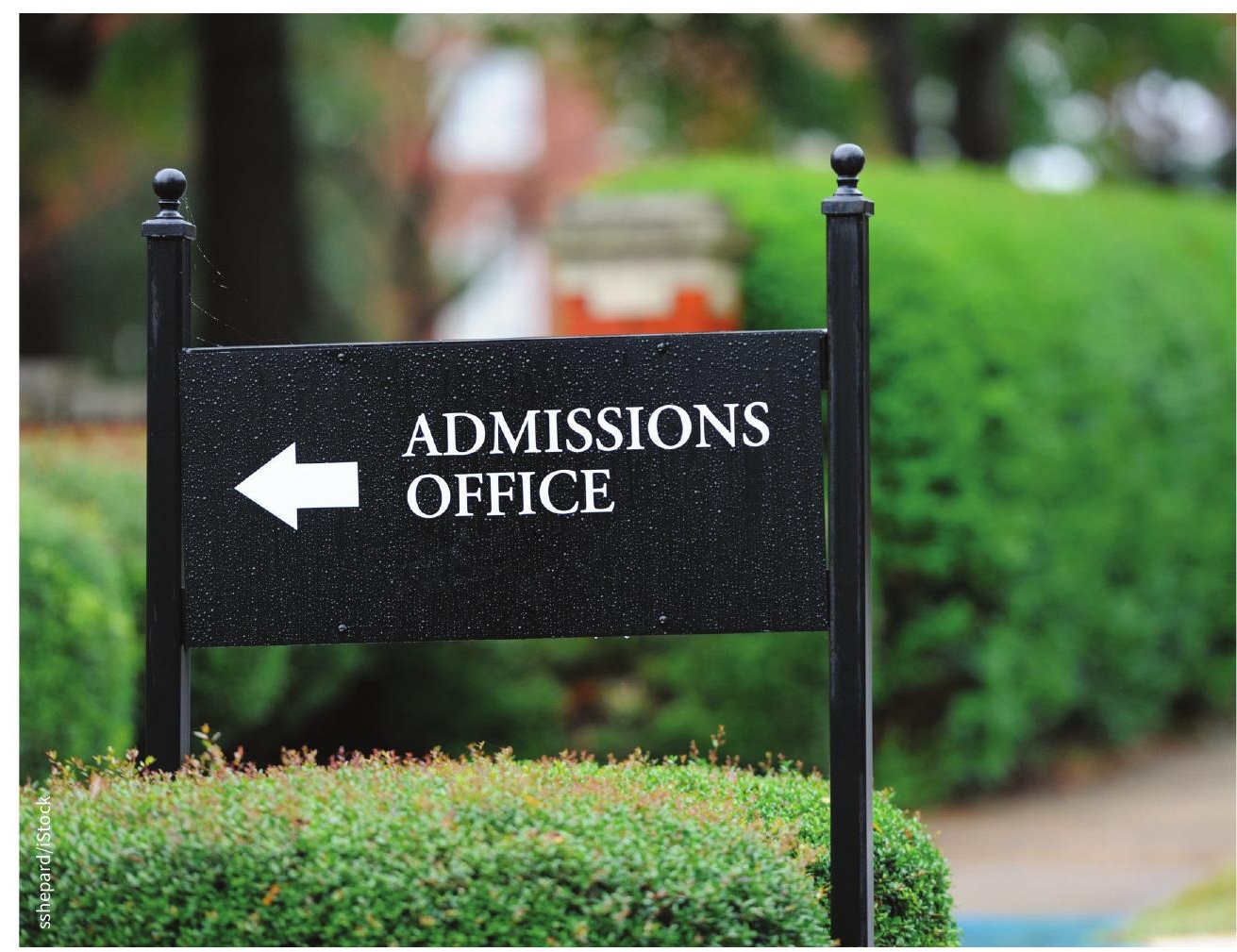

One reason for the low attrition rate in Canadian medical schools is the thorough and rigorous admissions process.

academic performance. One British medical charity is so concerned about the problem that it recently launched a campaign called Med Students Matter to highlight the importance of supporting the well-being of medical students, to reduce mental and financial pressures, so they can complete their training.

Dr. Eugene Yeung, who trained in the UK but now works at The Ottawa Hospital, says part of the reason for the high attrition rate in the UK is that many schools don't let those with grades in the lowest decile continue. Even those who are doing well sometimes choose to leave because of the pressure. "I don't think the bell curve system is very good for the wellbeing of the medical students," said Yeung. "And it costs taxpayers a lot of money."

The admissions model in some countries, like the UK, is to admit a lot of students and make them prove themselves. In Canada, however, the focus is on identifying the students who will thrive from the get-go.

"We have a very low drop-out rate and I think that's because of the rigour that is the admissions process," said Dr. Margo Mountjoy, a regional assistant dean for McMaster University's medical school. Mountjoy also pointed out that McMaster and other schools are "trying to put a bit 
more emphasis" on nonclinical careers so students know they have other options after they graduate.

Another difference is that schools in Canada put a greater emphasis on guiding students academically and supporting their mental health. "In the UK, that support is there, but mostly in the clinical years. Once they made it that far, they want to keep them," said Yeung.

There is no clear profile of a medical student who is likely to drop out, from a gender or socioeconomic background standpoint, but one indicator is a feeling of social isolation, according to a 2013 study published in BMC Medical Education that explored medical student attrition.

Feeling socially isolated is compounded when students think nobody will understand their doubts. "Medical students have invested so much into their career that it's hard for them to acknowledge, themselves, that they're having second thoughts," said Dr. Allyn Walsh, a professor of family medicine at McMaster University.

Fortunately, she said, most students considering dropping out go on to be successful doctors. "It's quite common for students to have an idea at some point along their careers - I know I certainly did - is this worth it?"
She recommends that educators and support staff normalize that feeling. "People need to be reassured that the feeling is common and it's transitory in most cases," she said. According to a US study, $11 \%$ of medical students consider quitting every year.

Walsh recommends reaching out to those who seem isolated and providing individualized support. "We want to make sure that if someone does decide to leave, they've been given all the supports that they've needed and that their decisionmaking is well thought out," she said. Supports may include personal counselling, help with learning and studying techniques, and accommodations such as lightening the course load.

Some students consider leaving in the academically demanding early years of medical school, but others who excel in the classroom environment may begin to feel "imposter syndrome" in the clinical years, said Walsh. "It always feels that everybody else seems to know more and be doing better."

Sometimes, however, dropping out may be the best decision a medical student can make. Tennessee-based Jeremy Weaver came from what he calls a "medical family." His father is a surgeon and many of his aunts and uncles are nurses and doctors. "I saw that as what success was." He wanted to be financially successful and able to travel the world and do medical missions, so it seemed natural to apply to medical school.

As he met his instructors, however, he didn't find a role model he wanted to emulate, and he stood out from fellow students for wanting to leave after a 12-hour day. "The work-life balance was not there," he said.

The feeling of wanting to drop out was an ever-present "elephant on my chest," and he finally acknowledged it early into his second year. He remembers his academic dean telling him that many students who perhaps should drop out choose to stay for fear of disappointing others and themselves. Weaver, who recently sold his shares in a successful tiny homes company he cofounded, has no regrets.

Today, he recommends that pre-med students spend a lot of time shadowing doctors to understand the day-to-day work involved in being a physician. "My advice is try not to get wrapped up in money or the respect," he says. "Get a really good sense of what the actual job is like."

Wendy Glauser, Toronto, Ont. 